\title{
Complementary Split Ring Resonator Based Triple Band Microstrip Antenna for WLAN/WiMAX Applications
}

\author{
Wael ALI ${ }^{1}$, Ehab HAMAD ${ }^{2}$, Mohamed BASSIUNY $Y^{3}$, Mohamed HAMDALLAH ${ }^{3}$ \\ ${ }^{1}$ Dept. of Electronics \& Comm. Engineering, College of Engineering, Arab Academy for Science, Technology and \\ Maritime Transport (AASTMT), Alexandria, Egypt \\ ${ }^{2}$ Dept. of Electrical Engineering, Aswan Faculty of Engineering, Aswan University, Aswan 81542, Egypt \\ ${ }^{3}$ Dept. of Electronics \& Comm. Engineering, College of Engineering, Arab Academy for Science, Technology and \\ Maritime Transport (AASTMT), Aswan, Egypt
}

wael_abd_ellatif@yahoo.com, e.hamad@aswu.edu.eg, atefrana@yahoo.com,eng_zakaria_aast@yahoo.com

Submitted August 19, 2016 / Accepted October 30, 2016

\begin{abstract}
A new simple design of a triple-band microstrip antenna using metamaterial concept is presented in this paper. Multi-unit cell was the key of the multi resonance response that was obtained by etching two circular and one rectangular split ring resonator (SRR) unit cells in the ground plane of a conventional patch operating at $3.56 \mathrm{GHz}$. The circular unit cells are resonating at $5.6 \mathrm{GHz}$ for the upper band of Wi-MAX, while the rectangular cell is designed to produce a resonance at $2.45 \mathrm{GHz}$ for the lower band of WLAN. WiMAX's/WLAN's operating bands are covered by the triple resonances which are achieved by the proposed antenna with quite enhanced performance. A detailed parametric study of the placement for the metamaterial unit cells is introduced and the most suitable positions are chosen to be the place of the unit cells for enhanced performance. A good consistency between simulation and measurement confirms the ability of the proposed antenna to achieve an improved gain at the three different frequencies.
\end{abstract}

\section{Keywords}

Metamaterial, metasurface, multi band antennas, CSRR, split ring resonators

\section{Introduction}

Microstrip patch antennas are the preferable type of antennas used for wireless communication systems, because of their attractive features such as light weight, low profile, low cost, easy fabrication, and compatibility with planar monolithic microwave integrated circuit (MMIC) components [1]. Various printed antenna topologies have been proposed by researchers for the purpose of enhancing their performance. One of these topologies can be achieved by changing the geometry of the patch itself or defecting the ground plane of the antenna as proposed in [2], where an antenna for ultra-high frequency application is designed.
Multi-circular shape of the patch in [3] was used to provide an enhanced performance of multiband antennas. Also, authors in [4] proposed a dual-band antenna realized by two different single-slotted single-band rectangular microstrip antennas.

Because of their fascinating properties, metamaterials are recently used for many applications in the field of antenna design [5]. There are a lot of antennas that have been developed based on metamaterials such as the antennas based on engineered dispersion curves ( $k-\beta$ diagram) [6], and the antennas based on the split-ring resonators (SRRs) and/or complementary split-ring resonators (CSRRs) [7]. Metamaterial antennas provide various techniques that can be used for improving antenna performance such as in [8] where TL-MTM technique is used to generate a multi band response. Metamaterial can also be used for enhancing the antenna parameters such as its bandwidth and gain. In [9], the design of a dual band antenna with an enhanced bandwidth is presented. In [10], metasurfaces are used to improve the gain of the antenna. In some applications, the main required feature for an antenna is its polarization and this parameter can also be controlled by using metamaterials in [11].

In this paper, a compact triple-band microstrip antenna based on CSRRs with two different geometries loaded on the ground plane is proposed. A conventional patch antenna operating at $3.6 \mathrm{GHz}$, which is operating in the middle WiMAX band $(3.2 \mathrm{GHz}$ to $3.8 \mathrm{GHz})$, is loaded on a ground plane with a rectangular CSRR of suitable dimensions that enables the excitation of the lower WLAN band $(2.4 \mathrm{GHz}$ to $2.484 \mathrm{GHz}$ ). Also, two circular CSRRs of suitable dimensions are loaded on the ground plane in order to resonate at the upper WiMAX frequency bands (5.25 GHz to $5.85 \mathrm{GHz}$ ). Finite Element Method (FEM) based software, Ansoft HFSS 13, is used for the analysis of the proposed antenna and optimizing its geometrical parameters. The main advantage of this proposed design over different multiband antenna designs is its accurate determination of all resonance frequencies i.e. every specific reso- 
nance frequency is corresponding to a specific resonator. Also, its relatively high radiation characteristics at the different achieved frequencies which make our design good candidate for WLAN/WiMAX applications.

\section{Antenna Design}

In this paper, a metamaterial-inspired rectangular antenna is introduced. A microstrip patch antenna operating at $3.6 \mathrm{GHz}$ is chosen as the reference design. The width and length of the patch antenna are $28 \mathrm{~mm}$ and $31 \mathrm{~mm}$, respectively with a copper thickness of $35 \mu \mathrm{m}$. The patch radiator is printed on Rogers RT/duroid 5880 (tm) substrate $\left(\varepsilon_{\mathrm{r}}=.2, \tan \delta=0.0009\right)$ with thickness of $1.575 \mathrm{~mm}$ as shown in Fig. 1. A microstrip inset feed is presented to perfectly match the patch radiator to the microstrip feed line that is characterized by width and length equal to $4.9 \mathrm{~mm}$ and $25 \mathrm{~mm}$, respectively. The feed line is inset to the patch with a value of $Y_{0}=6.5 \mathrm{~mm}$ and the two sides of the feed with a cut of width $W_{0}=5 \mathrm{~mm}$.

The reference antenna has a reasonable gain of $4.8 \mathrm{dBi}$ that will be affected by etching the ground plane with the unit cells. The return loss of the antenna is shown in Fig. 2 and it can be noticed that the antenna resonates at $3.56 \mathrm{GHz}$.

CSRRs, the complementary of the basic unit cells of metamaterials, are etched from the ground plane to reso-

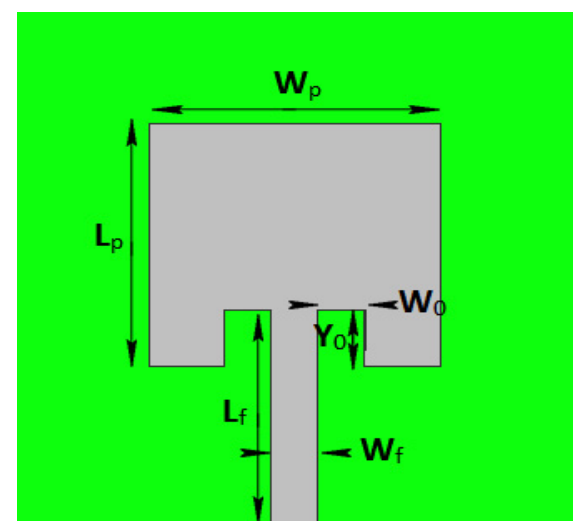

Fig. 1. Microstrip antenna operates at $3.6 \mathrm{GHz}$.

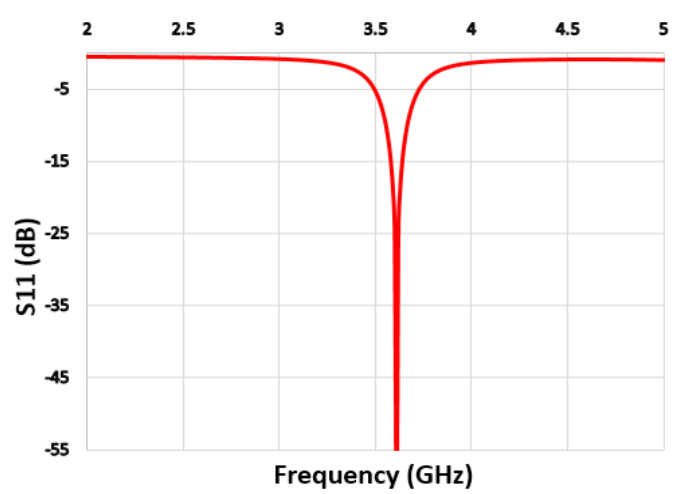

Fig. 2. $\mathrm{S}_{11}$ of the conventional microstrip antenna operates at 3.6 GHz.

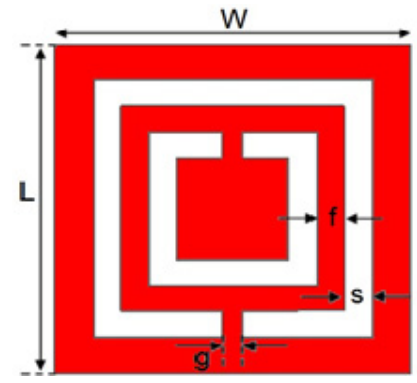

Fig. 3. Rectangular CSRR unit cell.

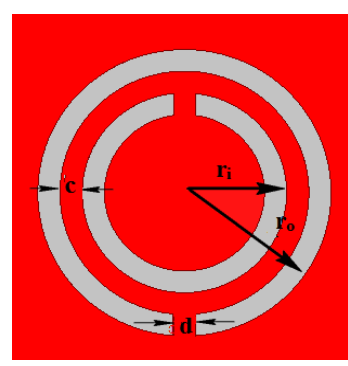

Fig. 4. Circular CSRR unit cell. nate at $2.45 \mathrm{GHz}$ and $5.3 \mathrm{GHz}$. The rectangular unit cell and the circular unit cell, shown in Fig. 3 and 4, are utilized to resonate at $2.45 \mathrm{GHz}$ and $5.3 \mathrm{GHz}$, respectively. The bandwidth of the SRR can be increased by widening the width of the unit cell as usual [12]. Two different shapes of CSRRs are used to achieve a resonance at $5.3 \mathrm{GHz}$ and $2.45 \mathrm{GHz}$ because the operating bandwidth of lower WLAN (2.4 to $2.484 \mathrm{GHz}$ ) is narrower than the operating bandwidth of upper WiMAX (5.25 to $5.85 \mathrm{GHz})$. Hence, there is no need to utilize a circular CSRR for achieving resonance at the $2.45 \mathrm{GHz}$ since it can provide a larger bandwidth than a rectangular CSRR as was mentioned in [13]. To test and extract the scattering parameters of this unit cell, the boundaries need to be adjusted as illustrated in Fig. 5. Perfect magnetic conductor (PMC) boundary condition sets on the left and right faces of the waveguide, and perfect electric conductor (PEC) boundary condition sets on the top and bottom of the waveguide. The scattering parameters are calculated over a suitable frequency range in order to determine the resonance frequency and the effective parameters caused by that unit cell. The incident TEM wave propagates in the $y$-axis direction. The E-field of the incident wave is polarized along the $z$-axis, and the $\mathrm{H}$-field is polarized along the $x$-axis. Figure 6 shows the $\mathrm{S}$ parameter characteristics of the rectangular CSRR and it can be observed that the rectangular unit cell resonates at $2.45 \mathrm{GHz}$ with a return loss equal to $-25 \mathrm{~dB}$ with narrower bandwidth, which make it suitable for lower WLAN band.

Figure 7 shows the negative permittivity characteristics of the rectangular CSRR which are extracted from the scattering parameters using the algorithm presented in [14]. In order to obtain a resonance at $5.3 \mathrm{GHz}$, a pair of circular CSRRs shown in Fig. 4 is etched from the ground plane.

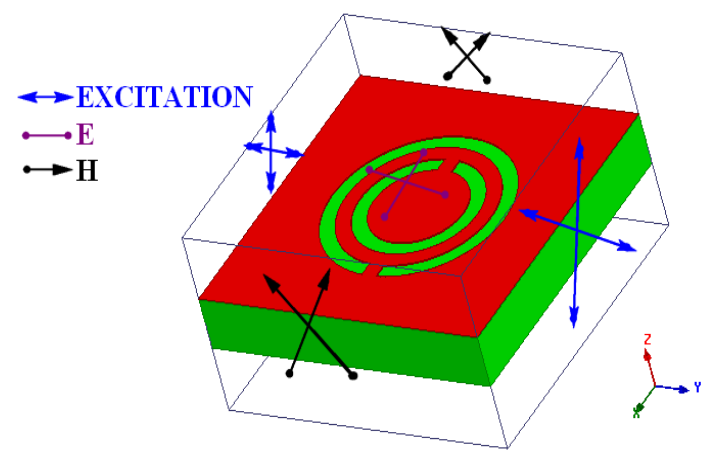

Fig. 5. The setup of the CSRR unit cell for transmission analysis. 


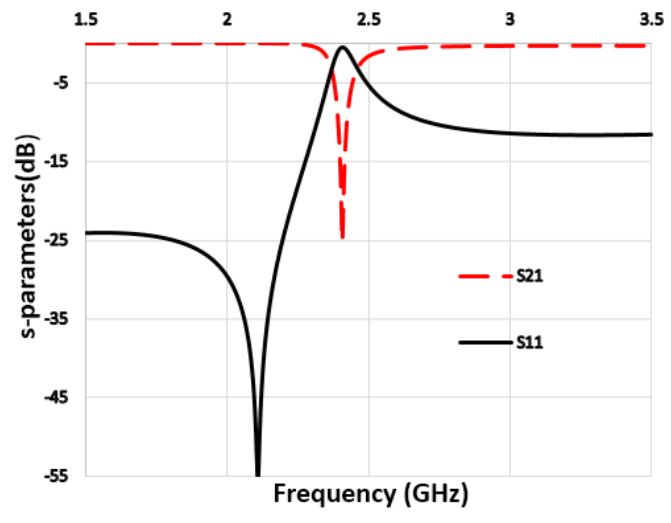

Fig. 6. S-parameters of the rectangular CSRR unit cell.

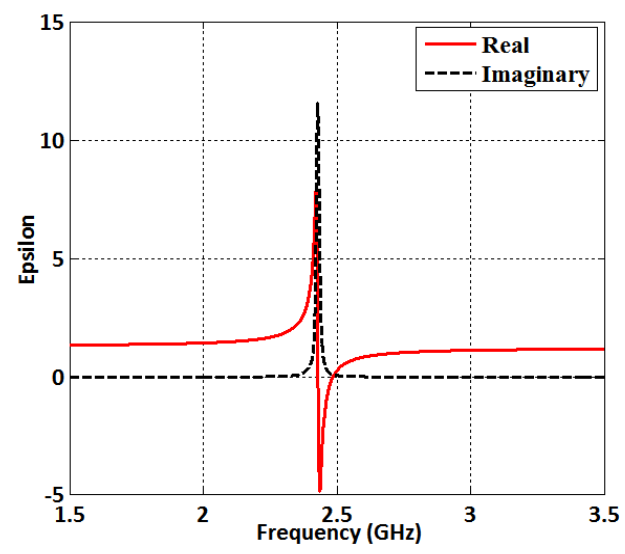

Fig. 7. Permittivity of the rectangular unit cell.

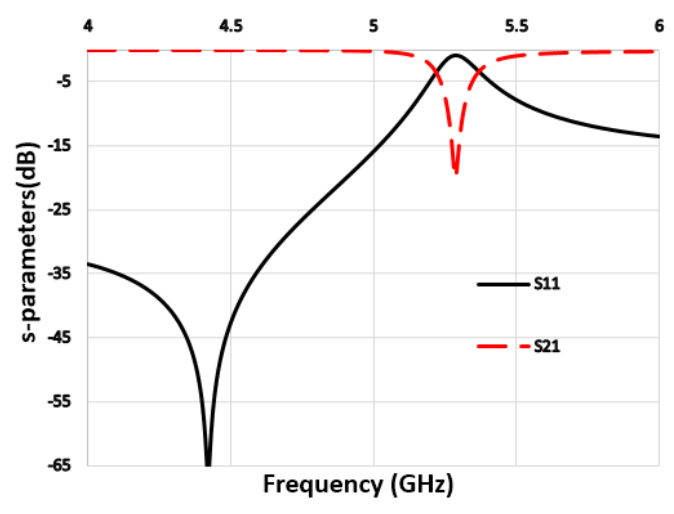

Fig. 8. S-parameters of the circular CSRR unit cell.

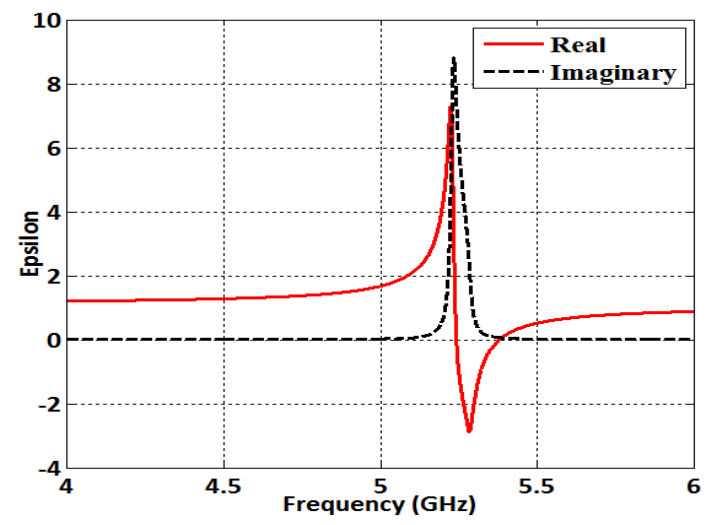

Fig. 9. Permittivity of the circular unit cell.

\begin{tabular}{|c|c|c|c|c|c|c|c|c|}
\hline Parameter & $L_{\mathrm{p}}$ & $W_{\mathrm{p}}$ & $Y_{0}$ & $W_{0}$ & $L_{\mathrm{f}}$ & $W_{\mathrm{f}}$ & $W$ & $L$ \\
\hline Value (mm) & 28 & 31 & 6.5 & 5 & 20 & 4.9 & 18 & 18 \\
\hline parameter & $G$ & $f$ & $s$ & $r_{\mathrm{o}}$ & $r_{\mathrm{i}}$ & $c$ & $d$ & \\
\hline Value (mm) & 0.5 & 1 & 2.5 & 3.3 & 2.3 & 0.5 & 0.5 & \\
\hline
\end{tabular}

Tab. 1. Optimal values of the proposed antenna dimensions.

Figure 8 demonstrates the S-parameter characteristics of the circular CSRR and it is obvious that the return loss is less than $-15 \mathrm{~dB}$ at $5.3 \mathrm{GHz}$ with a reasonable bandwidth for further operation in the upper WiMAX band. The negative permittivity characteristics of the circular CSRR that have been extracted following the same procedure used for the rectangular unit cell are shown in Fig. 9. The permittivity of CSRR unit cells are negative at the desired frequencies as expected, and that is the main feature of the metasurfaces [15]. All the optimal dimensions of the antenna and the unit cells are listed in Tab. 1.

\section{Simulation Results and Discussion}

The resonant frequency of the patch antenna without any CSRRs is $3.6 \mathrm{GHz}$. Embedding a rectangular unit cell of CSRR in the ground creates a second resonance at $2.45 \mathrm{GHz}$. Etching two circular unit cells generates the third resonance which is $5.3 \mathrm{GHz}$. The configuration of the proposed triple band antenna is demonstrated in Fig. 10.

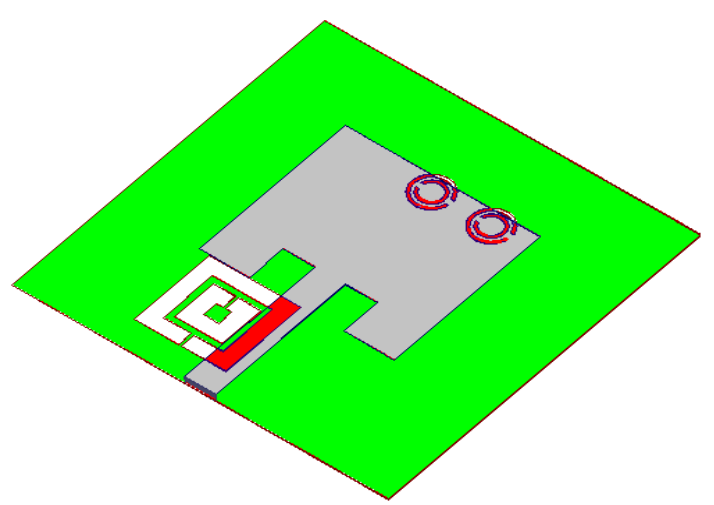

Fig. 10. Triple band microstrip antenna configuration.

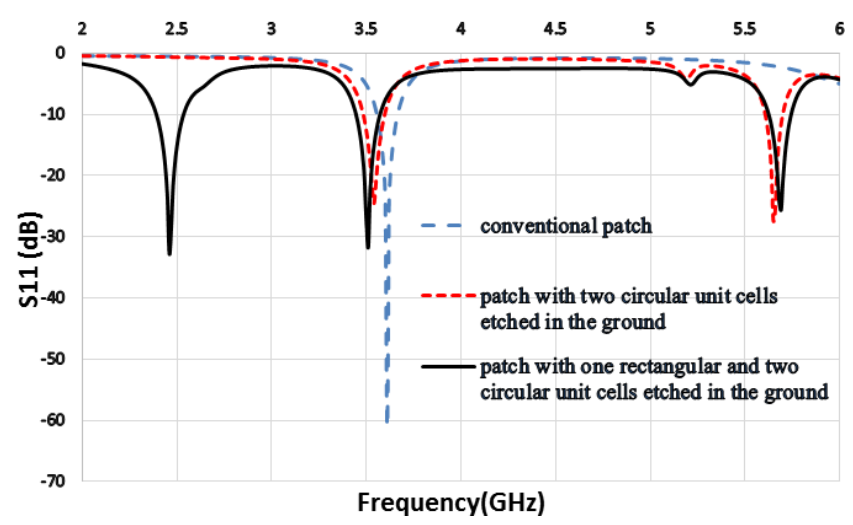

Fig. 11. S-parameters of the antenna at different configurations. 
It was expected to obtain the three resonant frequencies, each one corresponding to its generating element but the overall design response suffers from frequency shift and this discrepancy attributed to the mutual coupling between the unit cells was previously noticed in [16]. As a result of coupling effect, the resonance of the circular unit cell $(5.3 \mathrm{GHz})$ has been shifted to $5.6 \mathrm{GHz}$ and the resonance frequency of the patch $(3.6 \mathrm{GHz})$ is shifted to $3.5 \mathrm{GHz}$ as shown in Fig. 11.

\section{Parametric Study}

The parametric study in this section shows how the position of the rectangular and circular unit cells (without changing their dimensions) will affect the resonance frequencies at 2.45 and $5.6 \mathrm{GHz}$ in order to determine the definite position of the cells for proper operation.

\subsection{The First Resonance Corresponding to the Circular Unit Cell (Upper Resonance $5.6 \mathrm{GHz}$ )}

For some locations of the CSRRs in the ground plane as shown in Fig. 12, radiation efficiencies up to $96 \%$ can be achieved for both resonances. The simulated antenna in the parametric study has the same dimensions as the fabricated one, excluding the placement of the circular CSRR inside the ground, which varies from $c x=-13 \mathrm{~mm}$ to $-17 \mathrm{~mm}$ along $x$-axis direction. It should be noted that the reference point of all unit cells is $x=0, y=0$, which is the point where the patch is centered.

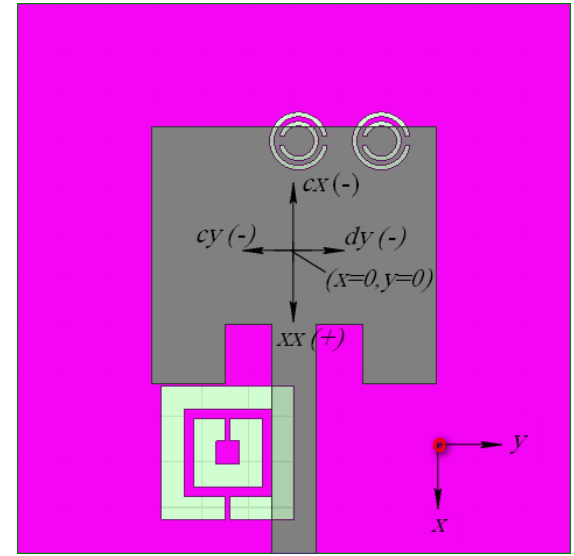

Fig. 12. CSRRs position study.

For y direction, the best position of the circular unit cell is chosen after the parametric study which was carried out from $c y=8.5 \mathrm{~mm}$ to $10.5 \mathrm{~mm}$ in the $y$-axis direction. Gaps of the unit cell are oriented in $y$-direction as this orientation matches its operating resonance frequency under the upper right corner of the patch. Another parametric study of $d y$, the distance between the centers of the two unit cells, is carried out. For simple clarification of the second circular unit cell's position, the reference point of $d y$ is chosen to be the center point of the first unit cell. The design of the patch with single circular unit cell can only achieve $3.7 \mathrm{dBi}$ peak realized gain with $79 \%$ radiation efficiency, so the second circular unit cell is used in order to increase the gain and the bandwidth at $5.6 \mathrm{GHz}$. Table 2 shows the best position of circular unit cells of this parametric study. The structure of the antenna containing two circular unit cells in the ground plane is fabricated to evaluate its effectiveness.

The fabricated prototype of the dual band antenna is shown in Fig. 13. A comparison between simulated and measured results is demonstrated in Fig. 14. The impedance characteristics of the proposed dual band antenna have been tested using R\&S ZVB 20 vector network analyzer (VNA). It can be observed from Fig. 14 that the antenna resonates at the two pre-specified frequencies but due to low fabrication accuracy, a loss of about $13 \mathrm{~dB}$ is presented at $3.6 \mathrm{GHz}$. Also, the resonance created by the circular unit cells at $5.6 \mathrm{GHz}$ has a little shift but with very low return loss.

\begin{tabular}{|c|c|c|}
\hline Position & First circular CSRR & Second circular CSRR \\
\hline At $x$-axis (mm) & -15 & -15 \\
\hline At $y$-axis (mm) & 9.5 & 0.5 \\
\hline
\end{tabular}

Tab. 2. Optimal positions of the proposed circular unit cells.

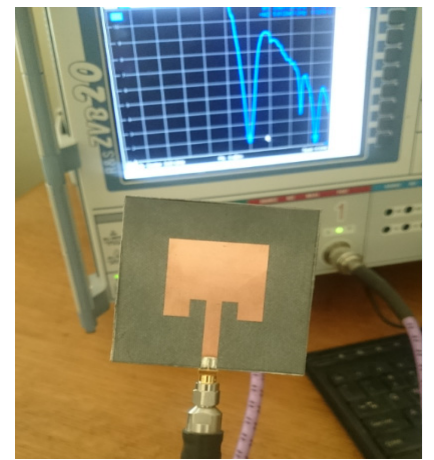

(a) Top view

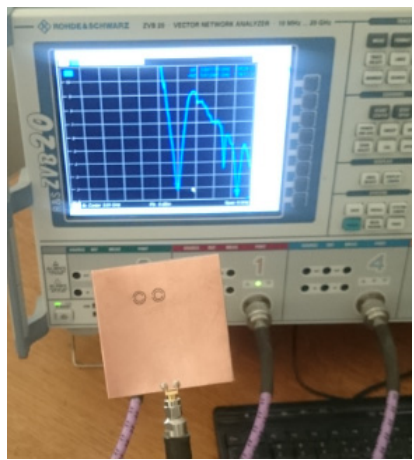

(b) Bottom view
Fig. 13. Fabricated prototype of the dual band antenna.

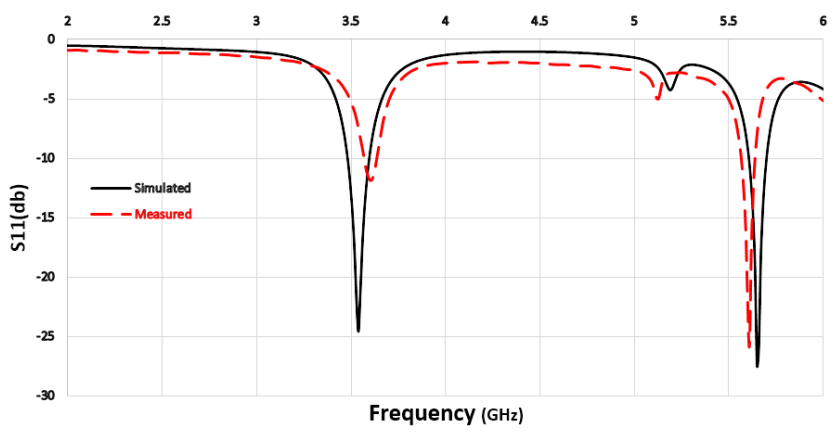

Fig. 14. Return loss comparison of the fabricated and simulated antenna. 


\subsection{The Second Resonance Corresponding to the Rectangular Unit Cell (Lower Resonance 2.45 GHz)}

After choosing the best position of the unit cells of the first resonance $(5.6 \mathrm{GHz})$, the next step is to optimize these cells with the new rectangular unit cell that will be etched from the ground plane to generate the second resonance $(2.45 \mathrm{GHz})$ in order to finally achieve the triple band behavior. The position of the rectangular unit cell was a field distribution-based selection. Regions with highly concentered electric field when the patch is excited at $2.45 \mathrm{GHz}$, need to be clarified for the purpose of finding the best regions on the ground plane for etching the new rectangular unit cell. Figure 15 shows the electric field distribution over the ground plane of the dual band model at $2.45 \mathrm{GHz}$.

The orientation of the unit cell (gaps are made in $x$-direction) was the suitable choice, as the unit cell with this orientation matches its operating resonance frequency. The unit cell is approximately positioned underneath the lower left corner of the patch where the field is intensively confined.

Figure 16 depicts the parametric study that can easily find the best position of the unit cell in $x$-direction only as the unit cell position in $y$-direction is $-7.2 \mathrm{~mm}$ from the center of the patch. After varying the position from $x x=17 \mathrm{~mm}$ to $x x=19 \mathrm{~mm}$, it can be noticed from Fig. 16

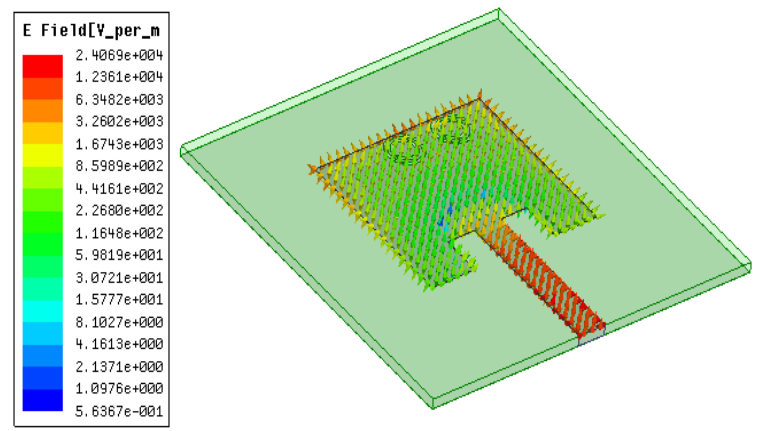

Fig. 15. Electric field distribution in the ground plane at $2.45 \mathrm{GHz}$.

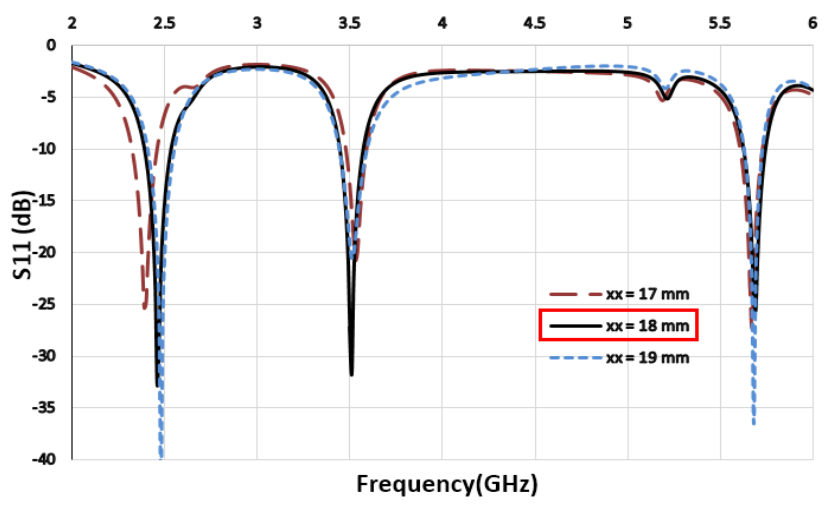

Fig. 16. Parametric study for the rectangular unit cell, operating at $2.45 \mathrm{GHz}$ notched in the ground, positioned in $x$ direction. that the best position of the rectangular unit cell in $x$-direction is $x x=18 \mathrm{~mm}$.

\section{Fabrication and Measurements}

The fabricated scheme, depicted in Fig. 17, gives satisfying results that match the simulated results. The simulated and measured return losses of the proposed triple band antenna are illustrated in Fig. 18. It can be observed from Fig. 18 that the fabricated prototype resonates at 2.45, 3.56, $5.62 \mathrm{GHz}$, respectively. Reasonable values of gain and radiation efficiency are achieved for each frequency but a little discrepancy occurs for the measured radiation efficiency at $2.45 \mathrm{GHz}$, due to the small distance between the SMA connector and the rectangular unit cell, which directly affects the gain at $2.45 \mathrm{GHz}$.

A comparison between simulated and measured radiation patterns is shown in Fig. 19 for the proposed triple band antenna. As investigated in Fig. 19, the simulated and measured $\mathrm{E}$ and $\mathrm{H}$ planes of radiation pattern of the proposed antenna at the three frequencies are mostly omnidirectional patterns with some ripples because the electrical size of the ground plane is reduced as a result of etching the three unit cells on it, resulting in partial absence of the reflector. Moreover, it can be observed from the radiation pattern of the two planes at $5.62 \mathrm{GHz}$ that the maximum radiation not in the broadside and this is due to the coupling effect between the two circular CSRRs. Also, the non-symmetric position of the two circular CSRRs on the ground plane may be a reason for that inclination of the

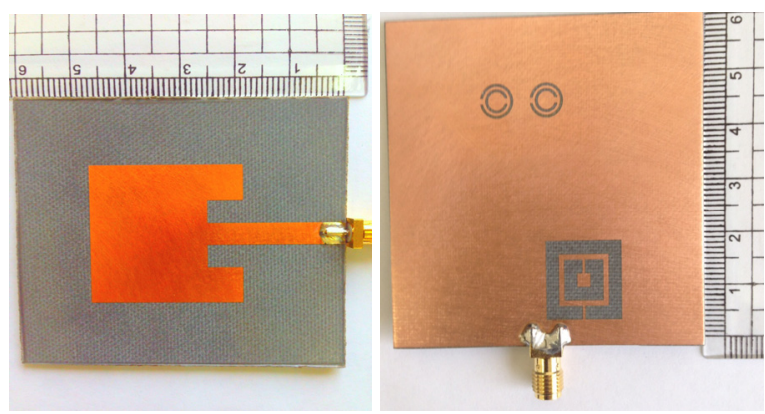

Fig. 17. Top and bottom view of the fabricated antenna.

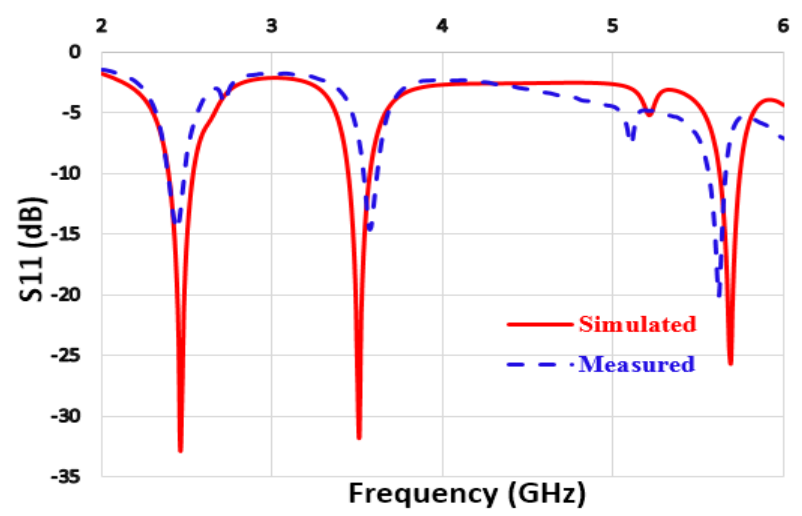

Fig. 18. Return loss comparison of the measured and simulated antenna. 


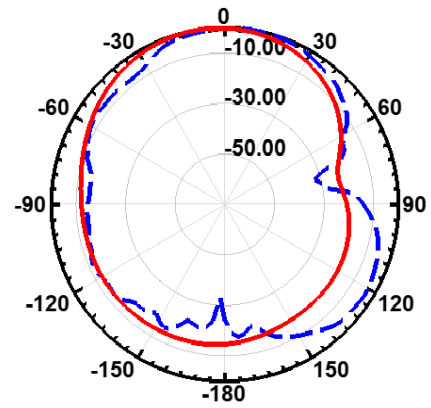

(a) E-plane at $2.45 \mathrm{GHz}$

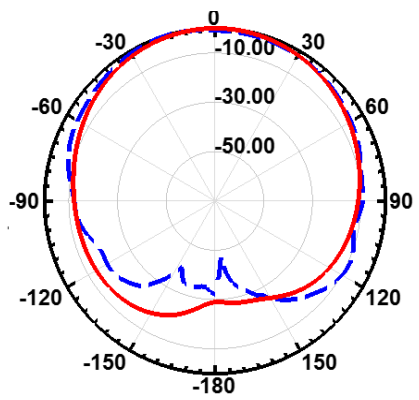

(c) E-plane at $3.56 \mathrm{GHz}$

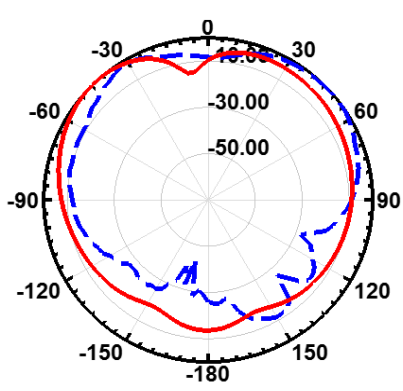

(e) E-plane at $5.62 \mathrm{GHz}$

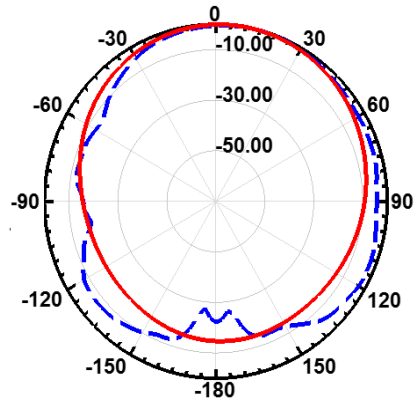

(b) H-plane at $2.45 \mathrm{GHz}$

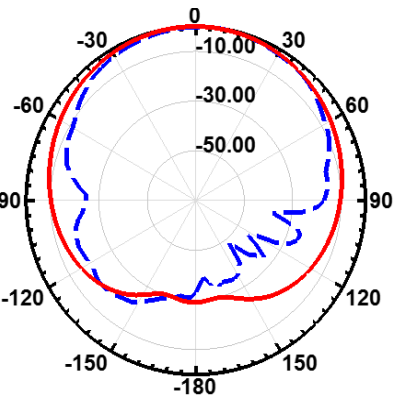

(d) H-plane at $3.56 \mathrm{GHz}$

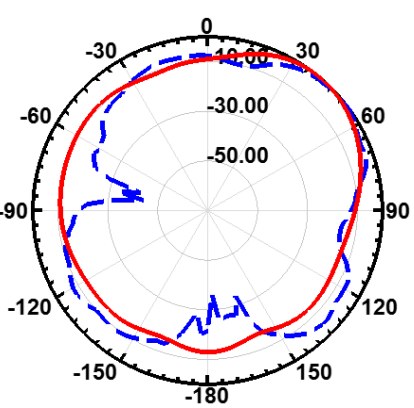

(f) $\mathrm{H}$-plane at $5.62 \mathrm{GHz}$

Simulation

Fig. 19. Simulated and measured $\mathrm{E}$ and $\mathrm{H}$ planes radiation patterns at the three frequencies.

beam. A good agreement between simulated and measured radiation patterns can be observed in the two planes.

The gain and radiation efficiency were measured using comparison method which required measuring the response of the standard antenna with a known gain (reference antenna). NSI-RF-RGP-10 probe with known parameters covering a range of frequencies $0.75-10 \mathrm{GHz}$ is used for measuring the response of the standard antenna to get cable losses effect and the free space loss. Then the proposed antenna response was measured and compared with the standard antenna to get rid of the losses and to compute the gain and radiation efficiency.

Fabrication tolerance, welding problems, and the SMA connector that almost touches the rectangular unit cell, were the main reasons of return loss and gain little discrepancies especially at $2.45 \mathrm{GHz}$. In order to evaluate the validity of the proposed triple band antenna, Table 3 presents a comparison between the proposed antenna and other designs in terms of measured values of resonance frequency, peak gain, and radiation efficiency. It can be demonstrated from this comparison that the proposed an-

\begin{tabular}{|c|c|c|c|}
\hline & $\begin{array}{c}\text { Resonance } \\
\text { frequencies(GHz) }\end{array}$ & $\begin{array}{c}\text { Measured } \\
\text { efficiency (\%) }\end{array}$ & Peak gain (dBi) \\
\hline \multirow{4}{*}{ [7] } & 2.4 & 43.7 & 0.27 \\
\cline { 2 - 4 } & 2.8 & 69.8 & 3.31 \\
\cline { 2 - 4 } & 3.4 & 77.6 & 4.45 \\
\hline \multirow{4}{*}[\mathbf{17}]{} & 2.17 & 57.6 & 0.9 \\
\cline { 2 - 4 } & 3.2 & 96.1 & 2.1 \\
\hline \multirow{3}{*}{$\begin{array}{c}\text { This } \\
\text { work }\end{array}$} & 5.25 & 80 & 2.85 \\
\cline { 2 - 4 } & 2.45 & 33.3 & 1.03 \\
\cline { 2 - 4 } & 3.56 & 29.3 & 5.1 \\
\hline
\end{tabular}

Tab. 3. Comparison between different metamaterial antenna designs.

tenna has higher gain when compared to the other antennas, even though it has lower efficiency due to fabrication tolerance as stated before.

\section{Conclusion}

A new design of triple band microstrip antenna printed on Rogers RT/duroid 5880 substrate was designed after studying the effect of etching metamaterial unit cells in the ground plane. Using two different types of meta-unit cells in the same design to generate multi-resonance response, was the main idea behind this work. Double circular CSRRs are loaded to the ground plane of microstrip antenna which operates at the middle Wi-MAX range (3.56 GHz) with $5.1 \mathrm{dBi}$ gain, lead to add a new resonance for WLAN at $5.6 \mathrm{GHz}$ with $5.41 \mathrm{dBi}$ gain. The lower resonance of Wi-MAX at $2.45 \mathrm{GHz}$ with $1.03 \mathrm{dBi}$ gain is added by loading a rectangular CSRR in the ground plane. Intensive EM simulations using 3D FEM-based EM simulator to optimize the positioning of the unit cells for coupling effect reduction between incorporated metamaterial cells were introduced. An acceptable consistency between the fabricated and simulated results has been achieved which makes the proposed antenna suitable for WLAN/ WiMAX applications.

\section{Acknowledgments}

The author would like to thank Eng. Nagdy in the National Telecommunication Institute (NTI) in Egypt for fabricating the proposed models and Dr. Hadia Elhennawy and Eng. Abdel Hamid Hatem for their support in measuring the radiation characteristics of the fabricated models in the anechoic chamber of Ain Shams University's antenna laboratory in Cairo, Egypt.

\section{References}

[1] BALANIS, C. A. Antenna Theory: Analysis and Design. 3rd ed. Wiley Interscience, 2005. (Fundamental parameters of antennas, p. 27-132.) ISBN $978-0471667827$ 
[2] PETRARIU, A. I., POPA, V. Analysis and design of a long range PTFE substrate UHF RFID tag for cargo container identification. Journal of Electrical Engineering, 2016, vol. 67, no. 1, p. 42-47. DOI: $10.1515 /$ jee-2016-006

[3] ESHTIAGHI, R., SHAYESTEH, M. G., ZAD-SHAKOOIAN, N Multi circular monopole antenna for multiband applications. IEEE Antennas and Wireless Propagation Letters, 2011, vol. 10, p. 1205-1207. DOI: 10.1109/LAWP.2011.217297

[4] CHAKRABORTY, U., KUNDU, A., CHOWDHURY, S. K., et al. Compact dual-band microstrip antenna for IEEE 802.11 a WLAN application. IEEE Antennas and Wireless Propagation Letters, 2014, vol. 13, p. 407-410. DOI: 10.1109/LAWP.2014.2307005

[5] DONG, Y., ITOH, T. Metamaterial-based antennas. Proceedings of the IEEE, 2012, vol. 100, no. 7, p. 2271-2285. DOI: 10.1109/JPROC.2012.2187631

[6] DONG, Y., TOYAO, H., ITOH, T. Compact circularly-polarized patch antenna loaded with metamaterial structures. IEEE Transactions on Antennas and Propagation, 2011, vol. 59, no. 11, p. 4329-4333. DOI: 10.1109/TAP.2011.2164223

[7] DONG, Y., TOYAO, H., ITOH, T. (2012). Design and characterization of miniaturized patch antennas loaded with complementary split-ring resonators. IEEE Transactions on Antennas and Propagation, 2012, vol. 60, no. 2, p. 772-785. DOI: 10.1109/TAP.2011.2173120

[8] SOliman, A. M., ELSHEAKH, D. M., ABDALLAH, E. A., et al. Inspired metamaterial quad-band printed inverted-F (IFA) antenna for USB applications. Applied Computational Electromagnetics Society Journal, 2015, vol. 30, no. 5, p. 564-570.

[9] ANEESH, M., KUMAR, A., SINGH, A., et al. Design and analysis of microstrip line feed toppled $\mathrm{T}$ shaped microstrip patch antenna using radial basis function neural network. Journal of Electrical Engineering and Technology, 2015, vol. 10, no. 2, p. 634-640. DOI: 10.5370/JEET.2015.10.2.634

[10] WU, Z., LI, L., LI, Y., CHEN, X. Metasurface superstrate antenna with wideband circular polarization for satellite communication application. IEEE Antennas and Wireless Propagation Letters, 2016, vol. 15, p. 374-377. DOI: 10.1109/LAWP.2015.2446505

[11] KAHNG, S., JEON, J., PARK, T. An orthogonally polarized negative resonance CRLH patch antenna. Journal of Electrical Engineering and Technology, 2015, vol. 10, no. 1, p. 331-337. DOI: 10.5370/JEET.2015.10.1.331

[12] TAMANDANI, A., AHMADI-SHOKOUH, J., TAVAKOLI, S. Wideband planar split ring resonator based metamaterials. Progress In Electromagnetics Research M, 2013, vol. 28, p. 115 to 128. DOI: $10.2528 /$ PIERM12120318

[13] BAGE, A., DAS, S. Studies of some non conventional split ring and complementary split ring resonators for waveguide band stop and band pass filter application. In The IEEE International Conference on Microwave and Photonics (ICMAP). Dhanbad (India), 2013, p. 1-5. DOI: 10.1109/ICMAP.2013. 6733474

[14] ZIOLKOWSKI, R. W. Design, fabrication, and testing of double negative metamaterials. IEEE Transactions on Antennas and Propagation, 2003, vol. 51, no. 7, p. 1516-1529. DOI: 10.1109/TAP.2003.813622

[15] FAlCONE, F., LOPETEGI, T., LASO, M. A. G., et al. Babinet principle applied to the design of metasurfaces and metamaterials. Physical Review Letters, 2004, vol. 93, no. 19, 197401. DOI: 10.1103/PhysRevLett.93.197401

[16] XIE, Y., LI, L., ZHU, C., LIANG, C. H. A novel dual-band patch antenna with complementary split ring resonators embedded in the ground plane. Progress In Electromagnetics Research Letters, 2011, vol. 25, p. 117-126. DOI: 10.2528/PIERL11062802
[17] GUPTA, A., SHARMA, S. K., CHAUDHARY, R. K. A compact CPW-fed metamaterial antenna for high efficiency and wideband applications. In The 21st National Conference on Communications (NCC). Bombay (India), 2015, p. 1-4. DOI: 10.1109/NCC.2015.7084825

\section{About the Authors ...}

Wael ALI received his B.Sc. and M.Sc. in Electronics and Communications Engineering from Arab Academy for Science, Technology and Maritime Transport (AASTMT), Alexandria, Egypt in 2004 and 2007, respectively. He obtained his Ph.D. in Electronics and Communications Engineering from Alexandria University, Alexandria, Egypt in 2012. He is a lecturer in AASTMT, Alexandria, Egypt. His research interests include smart antennas, microstrip antennas, microwave filters, and metamaterials.

Ehab HAMAD was born in Assiut, Egypt in 1970. He received his B.Sc. and M.Sc. in Electrical Engineering from Assiut University, Assiut, Egypt, in 1994 and 1999, respectively. He received his Ph.D. degree in Electrical Engineering from Otto-von-Guericke-University of Magdeburg, Magdeburg, Germany in 2006. He was a Teaching/ Research Assistant from 1996 to 2001 in Electrical Engineering Dep., South Valley University, Aswan, Egypt. From July 2001 to Dec. 2006, he was a Research Assistant in the Institute for Electronics, Signal Processing, and Communications, University of Magdeburg, Magdeburg, Germany. From July 2010 to April 2011, he joined the School of Computing \& Engineering, University of Huddersfield, UK as a Post-doctoral Research Assistant. Mr. Hamad is working now as an Associate Professor for Antennas and Microwave Engineering at Aswan Faculty of Engineering, Aswan University, Aswan, Egypt. Dr. Hamad is member of the Institute of Electrical and Electronics Engineers (IEEE) and a member of the Egyptian Syndicate of Engineers. He has authored about 35 research articles and his current research interests include antenna design, UWB antennas and metamaterials, RFID, RF MEMS as applied to microwave and millimeter-wave circuits, and microwave passive planar structures.

Mohamed BASSIUNY received his B.Sc. in Electronics and Communications Engineering from the Military Technical College (MTC) in 1977 and M.Sc. from Alexandria Engineering College, Alexandria, Egypt in 1982, and Ph.D. in Electronics and Communications Engineering from MTC, in 1988. He is a lecturer in AASTMT, Alexandria, Egypt. His research interests include smart antennas, digital signal processing.

Mohamed HAMDALLAH received his B.Sc. and M.Sc. in Electronics and Communications Engineering from Arab Academy for Science, Technology and Maritime Transport (AASTMT), Alexandria, Egypt in 2012 and 2016, respectively. He is a part-time teaching assistant in AASTMT, Aswan, Egypt. His research interests include microstrip antennas, and metamaterials. 